\title{
Pathways for the Recognition of the Intestinal Microbiota
}

\author{
Hans-Christian REINECKER \\ Gastrointestinal Unit and Center for the Study of Inflammatory Bowel Disease, Massachusetts General Hospital and Harvard Medical \\ School, USA
}

Received for publication, March 6, 2006

\begin{abstract}
The specific role of most of these newly discovered DC subsets in antigen sampling and presentation is unknown and it remains therefore unclear whether they work synergistically, as alternatives or have distinct functions in the recognition of the intestinal microbiota. The focus of effort in this field will be to understand how these diverse DC subsets cooperate in regulating the complex homeostasis and host defense in the different intestinal immune compartments. The intestinal lamina propria contains a DC network that serves as a newly discovered gateway for the uptake and transport of the intestinal microbiota. Specialized vesicular structures at the end of transepithelial dendrites serve as 'luminal sensors' for the mucosal immune system. Characterization of the surface components of these luminal sensors may aid in developing strategies to prevent bacterial and viral pathogen entry. We propose that the lamina propria and $M$ cell-dependent antigen sampling systems are associated with specific DC subsets. The discovery of functionally defined subsets of dendritic cells associated with distinct mechanisms responsible for the uptake of antigens across the intestinal barrier opens the path for strategies for targeting them specifically in the development of vaccines or treatment approaches for inflammatory bowel diseases. For these exciting possibilities to progress into practical applications, it needs to be established whether distinct DCs subsets are associated with multiple pathways or if their function is linked to specific innate or adaptive immune responses. Defining DC function in the intestine will be pivotal in finally progressing our understanding on how the mucosal immune system makes the distinction between commensal microbiota, pathogens and self antigens.
\end{abstract}

Key words: dendritic cells; chemokine receptors; intestinal microbiota; antigen sampling

\section{INTRODUCTION}

The intestine is monitored by a highly adaptable host defense system in which dendritic cells (DCs), macrophages and epithelial cells together monitor the microbial environment and coordinate immune responses to danger signals (1). Mucosal DCs are the critical antigen presenting cells responsible for priming of naïve $\mathrm{T}$ lymphocytes triggering the induction of adaptive immune responses to control tissue inflammation and to maintain immune tolerance $(2,3)$. The gastrointestinal mucosa is in constant interaction with the luminal microenvironment which contains commensal microbiota as well as a variety of bacterial, viral and protozoan pathogens. A single layer of intestinal epithelial cells (IEC) covers the $260-300 \mathrm{~m}^{2}$ of mucosal surface of the digestive tract. In this highly antigenic environment the mucosal immune system must maintain tolerance to commensal bacteria, food and self antigens while initiating defensive responses to pathogens to prevent uncontrolled infection of the host. By sampling pathogens and bacteria DCs and macrophages play an

*Corresponding author. Mailing address: Gastrointestinal Unit, Massachusetts General Hospital, Harvard Medical School, Jackson bldg. R711, Fruit Street, Boston MA 02114, USA

E-mail: hans-christian_reinecker@hms.harvard.edu important role in the immune defense of the gut (4-7). Interactions of DCs with antigen-specific T lymphocytes triggers the induction of adaptive immune responses and is also critical for the control of tissue inflammation and the maintenance of immune tolerance $(3,8-11)$. Evidence from numerous mouse models of inflammatory bowel disease (IBD) indicates that dysregulation of antigen recognition and processing of intestinal microbiota is a common disease mechanism (12). However, the cellular properties of mucosal DCs that determine uptake and presentation of antigens in the intestinal microenvironment are not well understood.

Recent studies have demonstrated that distinct macrophage and DC subsets may utilize diverse mechanisms to sample antigen in the intestine. Besides acquiring antigen in the lamina propria upon intestinal epithelial barrier breakdown, intestinal DCs located in intraepithelial pockets below the $\mathrm{M}$ cells may detect incoming pathogens and phagocytose them constitutively (13). Intestinal villous $\mathrm{M}$ cells may provide an additional system for passing intestinal microbiota to intestinal DCs (14). Furthermore, intestinal DCs appear to transport captured proteins from the gut lumen and fragments of epithelial cells themselves (15).

Recently, evidence was presented that intestinal DCs 


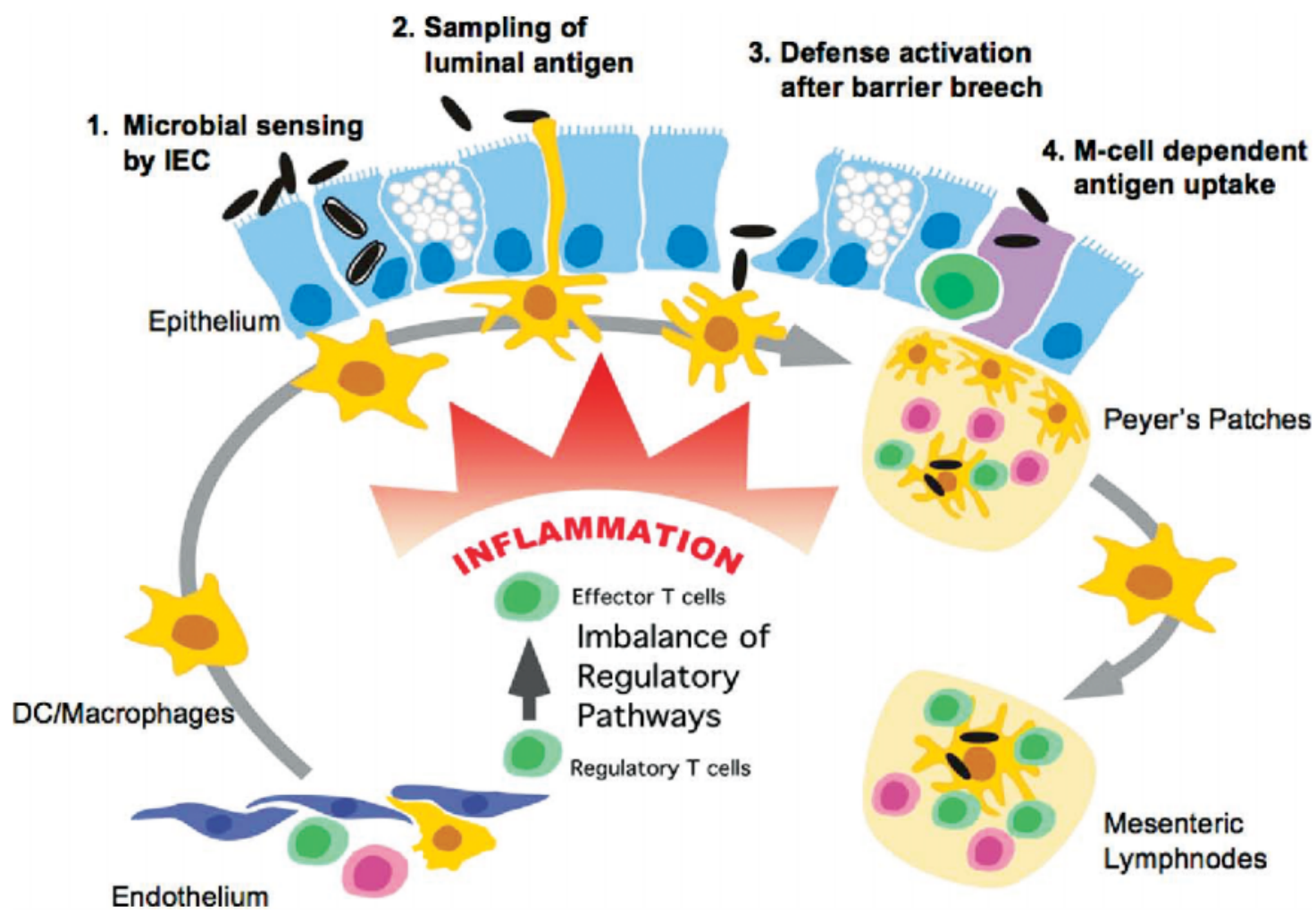

Fig. 1. Pathways for antigen acquisition by DCs in the intestine. Lamina propria DCs are derived from blood monocytes and undergo differentiation to immature DCs. DCs in the intestine can obtain information about the intestinal microbiota by different mechanisms which involve direct phagocytosis of antigens and the crosstalk with intestinal epithelial cells. DCs may present antigens either in the lamina propria, Peyer's patches, or mesenteric lymph nodes. Failure in the recognition of intestinal commensal or pathogenic bacteria may lead to the dysregulation of pathways governing $\mathrm{T}$ cell activation leading to intestinal inflammation (IEC: intestinal epithelial cells).

can also monitor the contents of the intestinal lumen by entering it directly or by extending dendrites through the intestinal epithelium, although the molecular basis of this mechanism remains to be elucidated $(16,17)$. In recent years it has become apparent that a diversity of DC lineages with distinct characteristics contribute to innate and adaptive immune responses in the intestine. While it has become increasingly evident that several mechanisms are involved in the translocation of antigens across the intestinal barrier, it is clear that mucosal DCs play a key role in the transport and processing of intestinal antigens for presentation in Peyer's patches (PPs) and mesenteric lymph nodes (MLNs) (Fig. 1). We now present evidence that distinct DC subsets are associated with these pathways as we begin to unravel their function in specific innate or adaptive immune responses.

\section{MATERIALS AND METHODS}

Mice

Mice with a target deletion of $\mathrm{CX}_{3} \mathrm{CR} 1$ or CCR6 with green fluorescence protein (GFP) insertion were previously described $(18,19)$. This approach allowed the generation of a mutant $\mathrm{CX}_{3} \mathrm{CR} 1$ or CCR6 locus and also the examination of the $\mathrm{CX}_{3} \mathrm{CR} 1$ or CCR6 expression pattern and migration of cells that normally express $\mathrm{CX}_{3} \mathrm{CR} 1$ or CCR6. All transgenic mice strains were bred and maintained in our specific pathogen-free animal facility according to institutional guidelines. All experiments were carried out with mice at 6 to 12 weeks of age according to protocols approved by the Subcommittee on Research Animal Care at the Massachusetts General Hospital and Harvard Medical School.

Isolation of PPs and small intestinal lamina propria DCs

PPs were crushed between frosted glass slides, washed twice in phosphate buffered Saline (PBS; Bio Whittaker ${ }^{\mathrm{TM}}$ ) with $1 \%$ bovine serum albumin (BSA) and $0.01 \% \mathrm{NaN}_{3}$ and then cells were stained with a cocktail of antibodies. Small intestines were inverted on 
polyethylene tubes (outer diameter $2.08 \mathrm{~mm}$, Becton Dickenson), washed with calcium and magnesium free PBS, and the mucus removed with $1 \mathrm{mM}$ dithiothreitol (DTT; Sigma). The intestinal epithelium was eluted with $30 \mathrm{mM}$ EDTA, followed by digestion of the tissue with $36 \mathrm{U} / \mathrm{ml}$ type IV collagenase (Sigma) and $150 \mu \mathrm{g}$ DNase $\mathrm{I}$ (Roche) in $5 \% \mathrm{FCS} / \mathrm{DMEM}$ for $90 \mathrm{~min}$ at $37^{\circ} \mathrm{C}$ in a $5 \%$ $\mathrm{CO}_{2}$ humidified atmosphere. The digested tissue was passed through a Cell Strainer (40 $\mu \mathrm{m}$ Nylon; BD Falcon ${ }^{\mathrm{TM}}$ ) and washed with Dulbecco's modified Eagle's medium (DMEM; Cellgro ${ }^{\circledR}$ ).

Small intestinal lamina propria DCs are further enriched by performing an iodixanol (5,5'-[(2-hydroxy1-3 propanediyl)-bis(acetylamino)] bis [N,N'-bis $(2,3$ dihydroxypropyl- 2,4,6 triiodo 1,3 benzenecarboxamide]) density gradient centrifugation. The dilution of $10 \mathrm{ml}$ of $30 \%$ iodixanol working solution with $21.4 \mathrm{ml}$ diluents $(0.8 \% \mathrm{NaCl}, 5 \mathrm{mM}$ EDTA, $10 \mathrm{mM}$ Tricine- $\mathrm{NaOH}, \mathrm{pH} 7.4$ ) yields an isoosmotic $9.5 \%$ iodixanol solution $(\rho=1.055 \mathrm{~g} / \mathrm{ml})$. Thirty percent iodixanol working solution has been previously prepared by mixing equal volumes of $60 \%$ iodixanol (OptiPrep ${ }^{\circledR}$; Axis Shield, Oslo, Norway) with diluents $(0.8 \% \mathrm{NaCl}, 5$ mM EDTA, 10 mM Tricine-NaOH, pH 7.4). Lamina propria leukocyte isolates are resuspended in $12 \mathrm{ml} \mathrm{9.5 \%}$ iodixanol solution. Eight $\mathrm{ml}$ inactivated fetal calf serum (FCS; Biotechnics Research Inc.) is layered on top of this cell suspension, followed by centrifugation at $1700 \mathrm{~g}$ for $10 \mathrm{~min}$ at $20^{\circ} \mathrm{C}$. DCs are harvested by transferring the FCS layer to $15 \mathrm{ml}$ polypropylene conical tubes (Falcon). Mixing the transferred FCS with $10 \mathrm{ml}$ DMEM $\left(\right.$ Cellgro $\left.^{\circledR}\right)$ dilutes the DC suspension. Lamina propria DCs are pelleted by centrifugation at $1700 \mathrm{~g}$ for $10 \mathrm{~min}$ at $5^{\circ} \mathrm{C}$ and washed in medium followed by centrifugation at $500 \mathrm{~g}$ for $7 \mathrm{~min}$ at $5^{\circ} \mathrm{C}$.

\section{HE staining}

$5 \mu \mathrm{m}$ cryostat sections are placed in haematoxylin for $5 \mathrm{~min}$, rinsed with deionized water, and stain is developed with tap water. Sections are destained by dipping slides 8 to 12 times in acid ethanol and rinsing in tap and dionized water. Sections are stained with eosin for $45 \mathrm{sec}$, dehydrated and covered by using the xylene based PerMount (Fisher Scientific). Sections are analyzed using an Olympus AX 70 microscope.

\section{Flow cytometry}

Isolated mouse lamina propria DCs are incubated in $10 \%$ donkey serum (Santa Cruz) for $20 \mathrm{~min}$ at $4{ }^{\circ} \mathrm{C}$ in FACS buffer $(0.2 \%$ BSA, $0.1 \%$ sodium azide in PBS), and then stained with PE-conjugated antibodies (anti-
CD80, -CD86, -CD11c, -CD11b, -CD16, CD4, (all from PharMingen) and or biotin-conjugated antibodies (anti$\mathrm{CD} 11 \mathrm{c}$, and $-\mathrm{I}-\mathrm{Ab}$ (all from PharMingen) followed by Cy-Chrome ${ }^{\mathrm{TM}}$ conjugated streptavidin (from PharMingen). DC isolates are then analyzed on a FACSCalibur cytometer using CellQuest software (Becton Dickenson).

Confocal microscopy and $3 D$ tissue reconstruction of living PPS

$M$ cells or intestinal epithelial cells (IECs) of living mucus-free PPs or small intestines were stained with Ulex europaeus agglutinin (UEA) conjugated with Rhodamin (Vector Laboratories) or with wheat germ agglutinin (WGA) conjugated with Texas Red (Molecular Probes) at concentrations of $20 \mu \mathrm{g} / \mathrm{ml}$ for 1 hour. Living intestinal tissues were imaged with a BioRad Radiance 2000 confocal microscope using multitracking (line switching) for two-color imaging. Image acquisition was carried out with LaserSharp Scanning Software, and 3D reconstructions and cell volume analysis were completed with Volocity software.

\section{RESULTS AND DISCUSSION}

To characterize the origin and functional diversity of intestinal mononuclear phagocytes responsible for recognition of intestinal pathogens we have utilized GFP-reporter mice, which allow the characterization of myeloid derived macrophages and DC subsets and their antigen sampling and immune regulatory properties. Using 3D reconstructive confocal microscopy in living tissues and optimized intestinal DC isolation techniques, we found that the small intestinal lamina propria is colonized by myeloid derived $\mathrm{CD} 11 \mathrm{c}^{+} \mathrm{DC}$ populations which are distinguished by their expression levels of either CD11c or $\mathrm{CX}_{3} \mathrm{CR} 1 . \mathrm{CX}_{3} \mathrm{CR} 1^{+} \mathrm{CD} 11 \mathrm{c}^{+} \mathrm{DCs}$ populate the entire lamina propria and can potentially sample antigens at the basolateral surfaces of intestinal epithelial cells in the jejunum, proximal ileum and the colon. In addition, intestinal DCs extend transepithelial dendrites into the terminal ileum in a process that requires $\mathrm{CX}_{3} \mathrm{CR} 1$. The intestinal microbiota provides the essential stimuli for the development of CD11 $\mathrm{c}^{+} \mathrm{DCs}$ in the terminal ileum. The ability of intestinal macrophages and DCs to phagocytose and clear Salmonella typhimurium occurs only if $\mathrm{CX}_{3} \mathrm{CR} 1$ is present. Our study thus assigns functional significance to the role of the $\mathrm{CX}_{3} \mathrm{CL} 1 / \mathrm{CX}_{3} \mathrm{CR} 1$ ligand/receptor in the regulation of the major myeloid-derived intestinal DC subset responsible for antigen sampling and host defense in the intestinal lamina propria. 
It has previously been shown that intestinal epithelial cells and endothelial cells in the lamina propria express the membrane-bound chemokine $\mathrm{CX}_{3} \mathrm{CL} 1 /$ fractalkine $(20,21)$. In order to identify the cellular targets of IECderived fractalkine, we utilized mice in which one or both copies of the $c x_{3} c r l$ allele was replaced with a gene encoding GFP (18). In these mice, GFP expression is under the control of the $\mathrm{CX}_{3} \mathrm{CR} 1$ promoter and, consequently, heterozygous mice $\left(c x_{3} c r l^{G F P /+}\right)$ express the receptor and GFP while homozygous mice $\left(c x_{3} c r 1^{G F P / G F P}\right)$ express GFP but are $\mathrm{CX}_{3} \mathrm{CR} 1$-deficient. GFP expression in these mice can be used to identify, isolate and characterize organ specific cell populations that normally express $\mathrm{CX}_{3} \mathrm{CR} 1$. In earlier studies, we found GFP and $\mathrm{CX}_{3} \mathrm{CR} 1$ expression in circulating monocytes and their progeny within tissues. No phenotypic or functional differences were detected in the peripheral lymphoid system between heterozygous and wild type mice (18), but $c x_{3} c r 1 G F P / G F P$ animals were found to have compromised migration of $\mathrm{CD} 16^{+}$ monocytes from blood into various tissues (22).

Examination of gut-associated tissues from $\mathrm{cx}_{3} \mathrm{crl} \mathrm{GFP} /+$ and $c x_{3} c r 1^{G F P / G F P}$ mice by confocal fluorescence microscopy revealed GFP-positive mononuclear cells in the lamina propria, PPs and MLNs. The isolated lamina propria leukocytes from $c x_{3} c r l^{G F P /+}$ mice represent different developmental stages of immature and mature DCs. The $\mathrm{GFP}^{+}$cells in both homozygous and heterozygous animals expressed CD11c, CD11b, CD4 and CD16/32 (23). The lamina propria cell isolations also contained $\mathrm{CD} 16^{+}$macrophages which did not express CD11c or $\mathrm{CX}_{3} \mathrm{CR} 1 / \mathrm{GFP}$.

CD $11 \mathrm{c}^{+} \mathrm{CD} 11 \mathrm{~b}^{+} \mathrm{DCs}$ from $c x_{3} c r 1^{G F P /+}$ and $c x_{3} c r l^{G F P / G F P}$ mice can be divided into subsets in which the $\mathrm{CX}_{3} \mathrm{CR} 1$ promoter is either activated or silent. $\mathrm{CX}_{3} \mathrm{CR} 1$ deficiency did not influence the relative percentage of CD $11 \mathrm{c}^{+} \mathrm{DCs}$ with active $\mathrm{CX}_{3} \mathrm{CR} 1$ promoter nor their expression levels of MHC class II, CD80, and CD86 which were similar to those observed in control C57BL/6 wild type mice (23).

CCR6 influences antigen recognition in the intestine by regulating the migration of $\mathrm{CD} 11 \mathrm{c}^{+} \mathrm{CD} 11 \mathrm{~b}^{+} \mathrm{DC}$ in response to CCL20 into the dome regions of the PPs (19, $24,25)$. Analysis of isolated lamina propria DC populations revealed a subdivision of $\mathrm{CD} 11 \mathrm{c}^{+}$cells into subsets, which can be distinguished by their level of $\mathrm{CD} 11 \mathrm{c}$ expression and co-expression of either $\mathrm{CX}_{3} \mathrm{CR} 1$ or CCR6.

Analysis of living intestinal tissues of $\operatorname{ccr} 6^{G F P /+}$ and $c x_{3} c r l^{G F P /+}$ mice revealed that CCR6 expression indeed characterizes the immune compartment of PPs. CCR6 ${ }^{+}$
DCs were found to be enriched in the PPs while $\mathrm{CX}_{3} \mathrm{CR} 1^{+}$DCs populated the entire lamina propria (LP), as well as PPs. CD11 ${ }^{+} \mathrm{CCR}^{+} \mathrm{DCs}$ are a distinct subset from CXRCR $1^{+}$DCs, which lack expression of CCR6. $\mathrm{CCR}^{+} \mathrm{B}$ cells were also detected in the PPs but occurred rarely in the lamina propria.

In $c c r 6^{G F P /+}$ and $c c r 6^{G F P / G F P}$ mice, GFP positive DCs were not observed within the follicle associated epithelium (FAE) or the dome regions of PPs, which contained a number of $\mathrm{GFP}^{+}$lymphocytes as determined by average cell volume. In contrast, $\mathrm{CX}_{3} \mathrm{CR} 1^{+} \mathrm{DCs}$ were normally closely associated with the FAE. Together, these experiments demonstrate that DC subsets in the intestine can be distinguished from one another based on chemokine receptor expression. Our experiments indicate that $\mathrm{CCR}^{+} \mathrm{DCs}$ are associated with antigen recognition in PPs, while $\mathrm{CX}_{3} \mathrm{CR} 1^{+}$DCs collect antigens from the lamina propria of the intestine and sample the intestinal microbiota through transepithelial dendrites $(13,23,26)$. However, it is not clear whether one particular subset or both participate in the activation of pathogen-specific $\mathrm{T}$ cells following oral infection with invasive pathogens.

\section{REFERENCES}

(1) Cook DN, Prosser DM, Forster R, Zhang J, Kuklin NA, Abbondanzo SJ, Niu XD, Chen SC, Manfra DJ, Wiekowski MT, Sullivan LM, Smith SR, Greenberg HB, Narula SK, Lipp M, Lira SA. 2000. CCR6 mediates dendritic cell localization, lymphocyte homeostasis, and immune responses in mucosal tissue. Immunity 12: 495-503.

(2) Fujii S, Liu K, Smith C, Bonito AJ, Steinman RM. 2004. The linkage of innate to adaptive immunity via maturing dendritic cells in vivo requires CD40 ligation in addition to antigen presentation and CD80/86 costimulation. J Exp Med 199: 1607-1618.

(3) Geissmann F, Jung S, Littman DR. 2003. Blood monocytes consist of two principal subsets with distinct migratory properties. Immunity 19: 71-82.

(4) Huang FP, Farquhar CF, Mabbott NA, Bruce ME, MacPherson GG. 2002. Migrating intestinal dendritic cells transport $\operatorname{PrP}(\mathrm{Sc})$ from the gut. J Gen Virol 83: 267-271.

(5) Iwasaki A, Kelsall BL. 1999. Freshly isolated Peyer's patch, but not spleen, dendritic cells produce interleukin 10 and induce the differentiation of $\mathrm{T}$ helper type 2 cells. J Exp Med 190: 229-239.

(6) Iwasaki A, Kelsall BL. 2000. Localization of distinct Peyer's patch dendritic cell subsets and their recruitment by chemokines macrophage inflammatory protein (MIP)-3alpha, MIP-3beta, and secondary lymphoid organ chemokine. J Exp Med 191: 13811394. 
(7) Jang $\mathrm{MH}$, Kweon MN, Iwatani K, Yamamoto M, Terahara K, Sasakawa C, Suzuki T, Nochi T, Yokota Y, Rennert PD, Hiroi T, Tamagawa H, Iijima H, Kunisawa J, Yuki Y, Kiyono H. 2004. Intestinal villous $M$ cells: an antigen entry site in the mucosal epithelium. Proc Natl Acad Sci USA 101: 6110-6115.

(8) Jung S, Aliberti J, Graemmel P, Sunshine MJ, Kreutzberg GW, Sher A, Littman DR. 2000. Analysis of fractalkine receptor $\mathrm{CX}(3) \mathrm{CR} 1$ function by targeted deletion and green fluorescent protein reporter gene insertion. Mol Cell Biol 20: 4106-4114.

(9) Kelsall BL, Biron CA, Sharma O, Kaye PM. 2002. Dendritic cells at the host-pathogen interface. Nat Immunol 3: 699-702.

(10) Kelsall BL, Biron CA, Sharma O, Kaye PM. 2002. Dendritic cells at the host-pathogen interface. Nat Immunol 3: 699-702.

(11) Kelsall BL, Strober W. 1996. Distinct populations of dendritic cells are present in the subepithelial dome and T cell regions of the murine Peyer's patch. J Exp Med 183: 237-247.

(12) Kobayashi H, Miura S, Nagata H, Tsuzuki Y, Hokari R, Ogino T, Watanabe C, Azuma T, Ishii H. 2004. In situ demonstration of dendritic cell migration from rat intestine to mesenteric lymph nodes: relationships to maturation and role of chemokines. J Leukoc Biol 75: 434-442.

(13) Lanzavecchia A, Sallusto F. 2001. Regulation of T cell immunity by dendritic cells. Cell 106: 263-266.

(14) Liu YJ. 2001. Dendritic cell subsets and lineages, and their functions in innate and adaptive immunity. Cell 106: 259-262.

(15) Lucas $\mathrm{AD}$, Chadwick N, Warren BF, Jewell DP, Gordon S, Powrie F, Greaves DR. 2001. The transmembrane form of the CX3CL1 chemokine fractalkine is expressed predominantly by epithelial cells in vivo. Am J Pathol 158: 855-866.

(16) Maric I, Holt PG, Perdue MH, Bienenstock J. 1996. Class II MHC antigen (Ia)-bearing dendritic cells in the epithelium of the rat intestine. J Immunol 156: 1408-1414.
(17) Mellman I, Steinman RM. 2001. Dendritic cells: specialized and regulated antigen processing machines. Cell 106: 255-258.

(18) Muehlhoefer A, Saubermann LJ, Gu X, LuedtkeHeckenkamp K, Xavier R, Blumberg RS, Podolsky DK, MacDermott RP, Reinecker HC. 2000. Fractalkine is an epithelial and endothelial cell-derived chemoattractant for intraepithelial lymphocytes in the small intestinal mucosa. J Immunol 164: 3368-3376.

(19) Nagler-Anderson C. 2001. Man the barrier! Strategic defences in the intestinal mucosa. Nat Rev Immunol 1: 59-67.

(20) Neutra MR, Frey A, Kraehenbuhl JP. 1996. Epithelial M cells: gateways for mucosal infection and immunization. Cell 86: 345-348.

(21) Niess JH, Brand S, Gu X, Landsman L, Jung S, McCormick BA, Vyas JM, Boes M, Ploegh HL, Fox JG, Littman DR, Reinecker HC. 2005. CX3CR1mediated dendritic cell access to the intestinal lumen and bacterial clearance. Science 307: 254-258.

(22) Niess JH, Reinecker HC. 2005. Lamina propria dendritic cells in the physiology and pathology of the gastrointestinal tract. Curr Opin Gastroenterol 21: 687-691.

(23) Podolsky DK. 2002. Inflammatory bowel disease. N Engl J Med 347: 417-429.

(24) Rescigno M, Urbano M, Valzasina B, Francolini M, Rotta G, Bonasio R, Granucci F, Kraehenbuhl JP, Ricciardi-Castagnoli P. 2001. Dendritic cells express tight junction proteins and penetrate gut epithelial monolayers to sample bacteria. Nat Immunol 2: 361367.

(25) Steinman RM, Hawiger D, Liu K, Bonifaz L, Bonnyay D, Mahnke K, Iyoda T, Ravetch J, Dhodapkar M, Inaba K, Nussenzweig M. 2003. Dendritic cell function in vivo during the steady state: a role in peripheral tolerance. Ann N Y Acad Sci 987: 15-25.

(26) Uhlig HH, Powrie F. 2003. Dendritic cells and the intestinal bacterial flora: a role for localized mucosal immune responses. J Clin Invest 112: 648-651. 